\title{
Subthalamic Nucleus: Neuroanatomical Review
}

\section{Núcleo subtalâmico: Revisão neuroanatômica}

\author{
Marcelo José Silva de Magalhães ${ }^{1}$ Claudiojanes dos Reis ${ }^{2} \quad$ Juliana Rabelo da Silva Sousa ${ }^{3}$ \\ Victória Souza Marques ${ }^{3}$ Tayná Cardoso Gonçalves ${ }^{3}$ lara Cristina Vieira Ribeiro ${ }^{3}$ \\ Leide Daiana Silveira Cardoso ${ }^{3}$ Victor Caribé Crosland Guimarães ${ }^{3}$ \\ Frederico Gustavo de Souza Marques ${ }^{3}$ Sarah Dias Pereira ${ }^{3}$
}

\footnotetext{
1 Department of Neurosurgery, Hospital Vila da Serra, Nova Lima, MG, Brazil

${ }^{2}$ Discipline of Anatomy, Faculdades Unidas do Norte de Minas

(FUNORTE), Montes Claros, MG Brazil

3 Faculdades Unidas do Norte de Minas (FUNORTE), Montes Claros, MG, Brazil
}

Arq Bras Neurocir 2020;39(4):284-288.

\begin{abstract}
Address for correspondence Marcelo José Silva de Magalhães, MD, MSc, Rua Francisco Versiane Ataide, 760, apartamento 1301., Montes Claros, MG, 39401-039, Brazil

(e-mail: marcelo7779@yahoo.com.br).
\end{abstract}

\begin{abstract}
Keywords

- subthalamic nucleus

- efferent pathways

- chorea

- Parkinson disease
\end{abstract}

\section{Resumo}

Discovered in 1865 by Jules Bernard Luys, the subthalamic nucleus is a set of small nuclei located in the diencephalon, inferior to the thalamus and superior to the substantia nigra, that can be visualized in a posterior coronal section. Histologically, it consists of neurons compactly distributed and filled with a large number of blood vessels and sparse myelinated fibers. This review presents an analysis of this anatomical region, considering what is most recent in the literature. Subthalamic neurons are excitatory and use glutamate as the neurotransmitter. In healthy individuals, these neurons are inhibited by nerve cells located in the side globus pallidus. However, if the fibers that make up the afferent circuit are damaged, the neurons become highly excitable, thus causing motor disturbances that can be classified as hyperkinetic, for example ballism and chorea, or hypokinetic, for example Parkinson disease (PD). The advent of deep brain stimulation has given the subthalamic nucleus great visibility. Studies reveal that the stimulation of this nucleus improves the motor symptoms of PD.

Descoberto em 1865 por Jules Bernard Luys, o núcleo subtalâmico (NST) é um conjunto de pequenos núcleos situados no diencéfalo, inferior ao tálamo e superior à substância negra, que pode ser visualizado em um corte coronal posterior. Histologicamente, consiste em neurônios distribuídos de forma compacta e preenchidos com um grande número de vasos sanguíneos e fibras mielinizadas dispersas. Esta revisão apresenta uma análise sobre essa região anatômica, considerando o que há na literatura a seu respeito. Os neurônios subtalâmicos são excitatórios e utilizam o glutamato como neurotransmissor. Em indivíduos saudáveis, esses neurônios são inibidos por células nervosas localizadas no globo pálido lateral. Contudo, se as fibras que compõem o circuito paleoestriado forem lesadas, os neurônios tornam-se altamente excitáveis, provocando assim distúrbios motores que podem ser classificados como: hipercinéticos, tais como balismo e coreia, ou hipocinéticos, por exemplo, doença de Parkinson (DP). O advento da estimulação cerebral profunda tem concedido grande visibilidade ao NST. Estudos destacam que a estimulação desse núcleo realmente ameniza os sintomas motores da DP. received

July 23, 2017

accepted

November 13, 2017
DOI https://doi.org/

10.1055/s-0037-1615268. ISSN 0103-5355.
Copyright $\odot 2020$ by Thieme Revinter

Publicações Ltda, Rio de Janeiro, Brazil
License terms

(c) $(1) \$$ 


\section{Introduction}

The subthalamic nucleus (STN) was described by Jules Bernard Luys, in 1985, as the "bandelette accessoire de l'olive supérieure" ("upper olive accessory range"), thus showing its relationship with the red nucleus, which was erroneously labeled as "superior olive." It was Auguste Forel who, in 1877, provided a more appropriate description and suggested the term corpus Luysii, a denomination still used for this nucleus. ${ }^{1}$ The STN is an important structure in the modulation of the activity of the base nuclei. It has a reciprocal connection with the pale globe, with which it maintains excitatory efferences that inhibit movement. Therefore, it is justified to assign the STN an inhibitory effect on the movement. ${ }^{2,3}$

In Luys' STN clinical studies, it was observed that the lesions of the connections of this nucleus could also produce contralateral hemichorea or hemiballism in humans. ${ }^{2}$ In addition, this structure has been implicated in the physiopathology of the Parkinson disease (PD). ${ }^{3}$

The present article aims to point out histological, anatomical and clinical considerations of the STN. This is a review of the anatomical aspects of this structure, highlighting, particularly, its topographic relations, its connections with other areas of the nervous system in the context of movement modulation, vascularization, histology and neurosurgical aspects agents through deep cerebral stimulation for PD treatment.

\section{Methodology}

The method used was a review of the literature, which allowed gathering, evaluating and summarizing the scientific evidence on the subject investigated to contribute to the development of knowledge in the theme.

The search for indexed publications in the following databases was performed in April 2017: Pub-Med, Scielo, and Web of Science. The following terms were used as descriptors in the search: "subthalamic nucleus," "subthalamic nucleus connections" and "clinical manifestations of the subthalamic nucleus."

The inclusion criteria were: articles published in Portuguese and English and their abstracts available in the databases. Articles that did not address the proposed theme were excluded.

Articles were selected with experimental design (clinical trials, randomized or not) or observational (case-control studies, cohort studies, and studies before and after) and studies conducted in humans, in which some of the following characteristics were evaluated: histology, anatomy, connections, and functions of the STN as well as the clinical manifestations associated with it. After reading the selected researches, the analysis was proceeded, and, later, the discussion.

\section{Discussion}

\section{Historical Aspects of the STN}

The STN was discovered in 1865 by the French researcher Jules Bernard Luys (1828-1897), who perceived it as a bridge to the dispersion of the cerebellar influence over the striated body, so that it would have "crucial role in the synthesis of automatic motor actions." In addition, Luys was the first to characterize this structure as intimately linked to the nuclei of the base. ${ }^{4}$

In his first and most important book, Luys described the STN as "bandelette accessoire de l'olive supérieure" ("upper olive accessory range"), an incorrect anatomical description, as critically noted by Auguste Forel (1848-1931), who remade the description of the subthalamic gray formation in an article in which one can read: "This term is inappropriate for at least three reasons"1,2 (-Fig. $\mathbf{1}$ ).

\section{Neuroanatomical Limits of STN}

In some coronary sections of the cerebrum in the posterior view, it is possible to locate the STN. It is an isoconvex nucleus that is located superiorly to the substantia nigra and to the tegument of the mesencephalon and, caudally, to the hypothalamus. ${ }^{3}$ Medially limiting are: the nipple-thalamic fascicle and the third ventricle. At the upper limit, the tegmental area and the thalamus are visualized. Laterally, the white matter and the cerebral pedunculus (-Fig. 1). ${ }^{3}$

\section{Histological Considerations of the STN}

In rodents, it was found that the STN consists of neurons distributed compactly and filled with a large number of blood vessels and scattered myelinated fibers. It was possible to observe the cell body of the neurons with plenty of organelles, but with only a small amount of smooth and rough endoplasmic reticulum. The nucleus is presented with a widely invaginated nuclear wrap and pale nucleoplasm with little heterocromatine. Two types of axonic terminals were identified. The first type is a small terminal with medium-sized round vesicles (possibly glutamatergic) and asymmetric synapses, mainly with thin dendrites. The second type is a large terminal with round and slightly flattened vesicles (possibly GABAergic), presenting adhesion joints with their postsynaptic targets, in addition to symmetrical synapses, mainly with bigger cell bodies and larger dendrites. ${ }^{5}$

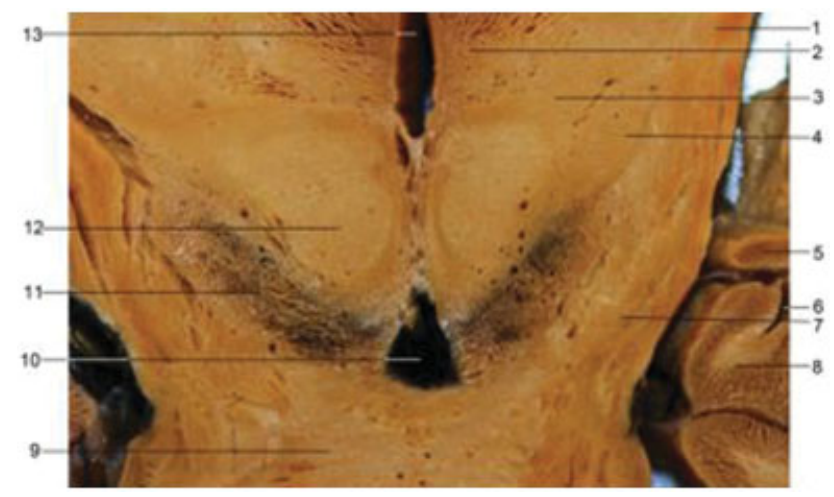

Fig. 1 Subthalamic nucleus in coronal section at the level of the red nucleus. 1-Internal capsule; 2-thalamus; 3-ventral tegmental area; 4-subthalamic nucleus; 5-Optical tract; 6-temporal horn of the lateral ventricle; 7-Cerebral peduncle; 8-Hippocampus; 9-bridge; 10-interpeduncular fossa; 11-substantia nigra; 12-red nucleus; 13-third ventricle. Source: Image courtesy of Marcelo JS Magalhães and Claudiojanes Reis. 
Three types of neurons have been described in cats:

- Type I neurons - they are the main constituents, having oval or polygonal cell bodies, average diameter of $26 \mu \mathrm{m}$ $\times 36 \mu \mathrm{m}$ and 4 to 6 primary dendrites.

- Type II neurons - they present multipolar or polygonal cell bodies, measuring on average $31 \times 43 \mu \mathrm{m}$ and emitting four to 7 primary dendrites.

- Type III neurons - they present polygonal cell bodies, measuring $23 \times 26 \mu \mathrm{m}$ on average and emitting 4 to 6 primary dendrites. $^{6}$

Yelnik $^{7}$ (1979), in a comparative approach, discovered only one variety of golgi neuron type I, which is identical in cats, monkeys, and humans. This type of neuron presents a cellular body and is in an ovoid form, which gives it a fusiform appearance when observed parallel to its long axis, while it seems circular or polygonal when observed from other directions. ${ }^{7}$

\section{Afferent and Efferent STN Fibers}

The STN receives afferences mainly from the cerebral cortex, the thalamus, the pale globe, and the brainstem. Regarding efferences, the STN has connections with the pale globe, the substantia nigra, the striated body and the brainstem. ${ }^{8}$

It is noteworthy that the STN is constituted mainly by projection neurons. ${ }^{5}$ Based on their axonal targets, five distinct types of projection neurons were identified ${ }^{9}$ :

- Neurons that were projected for the reticular part of the substantia nigra of the mesencephalon (BSt) and for the medial pale globe (MPG) and the lateral pale globe (LPG) segments (21.3\%).

- Neurons aiming at the BSt and LPG (2.7\%).

- Projecting neurons for the MPG and the LPG (48\%).

- Neurons targeting only the LPG (10.7\%).

- Neurons with axons that traveled the striated body, but whose terminal ramification could not be visualized in detail (17.3\%).

Cortico-subthalamic projections-in primates, these fibers emerge from the primary motor cortex, the supplementary motor area, the supplementary premotor area and the dorsal and ventral preengine cortex, the cingulate gyrus, the somatosensory cortex and the insular cortex. ${ }^{8-10}$ These projections predominantly innervate the dorsal aspect of the STN and are integral components in the motor circuits of the base nuclei. ${ }^{8-10}$

A complex intrinsic pattern of somatotopy was reported in the STN, in which multiple homuncles were described. ${ }^{8}$ The fibers of the primary motor cortex related to the leg, arm, and face are represented in the lateral area of the STN, while the medial portion of the nucleus receives fibers from the supplementary motor area, the dorsal premotor cortex, and the ventral premotor cortex, in an inverse somatotropic distribution (leg, arm and face, respectively, represented from medial to lateral). ${ }^{11}$

Projection of the pale globe-it comprises one of the main afferences. Practically the entire nucleus receives pallidal fibers, which are in the mediolateral and rostrocaudal directions. $^{12}$ The topographic and somatotropic distribution of

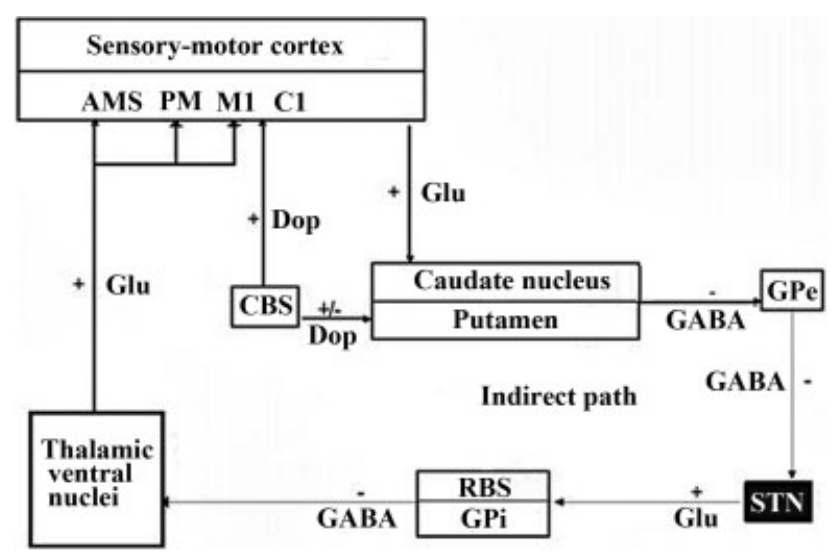

Fig. 2 The diagram representing the indirect pathway of the basal nuclei, involving the subthalamic nucleus (STN). Abbreviations: AMS, supplementary motor area; PM, pre-motor area; M1, primary motor area; $\mathrm{C} 1$, somesthetic cortex; Cns, a compact portion of the substantia nigra; $\mathrm{SNr}$, reticulated portion of the substantia nigra; GPi, Inner pale globe; GPe, external pale globe; Glu, glutamate; Dop, dopamine; GABA, gamma-aminobutyric acid. Signs $(p)$ indicate excitatory pathways and signs (-) indicate inhibitory pathways. Scheme based on Salzo (2009).

these afferences vary among the species. In rodents, the lateral areas of the pale globe innervate the lateral STN, while the median areas of the STN are innervated by the medial and ventral pale. ${ }^{12}$ It is important to stress that the LPG afferences belong to the indirect circuit of the base cores (-Fig. 2).

Efferences for the pale globe-the STN designs for both segments of the pale globe (LPG and MPG). Subthalamic nucleus fibers enter the pale globe through its posterior portion, traversing a caudorostral direction. ${ }^{12}$ The medial part of the STN projects mainly for the rostral LPG, the ventral pale and the rostral MPG (associative and limbic territory). The ventral portion of the STN is mainly associated with the dorsomedial region of the LPG and the MPG (associative territory). The caudal STN predominantly projects for the motor area of the LPG and the MPG. ${ }^{12}$ It is important to emphasize that the efferences for the MPG belong to the indirect circuit of the nuclei of the base. (-Fig. 2)

Efferences for the substantia nigra-STN fibers are associated with the substantia nigra mainly through its ventromedial region, spreading laterally in a rostrocaudal direction. ${ }^{12,13}$ Although most of these fibers infuse the reticular part, some axons ascend to the compact part, being one of the mechanisms responsible for releasing dopamine. ${ }^{12,13}$

Efferences for the striated body-the STN sends few projections to the striated body in rodents and primates. ${ }^{13}$ In primates, the ventricular associative and limbic regions of the STN innervate mainly to the caudate, while the dorsolateral motor portions of this nucleus innervated the putamen. $^{12}$ (- Table 1)

\section{Biochemical Aspects of NST}

Different neurotransmitters are found according to the connections established with the STN.

The cortico-subthalamic pathway connects its terminals with small dendrites in the STN through the neurotransmitter 
Table 1 Afferent and efferent fibers of the subthalamic ${ }^{9-13}$ nucleus

\begin{tabular}{|l|l|l|}
\hline & Afferences & Efferences \\
\hline Cortex & $\begin{array}{l}\text { Cortico-subthalamic } \\
\text { Motor cortex } \\
\text { Cingular cortex } \\
\text { Somato-sensorial } \\
\text { cortex } \\
\text { Insular cortexr }\end{array}$ & \\
\hline Pale globe & $\begin{array}{l}\text { Medial pale globe } \\
\text { Lateral pale globe }\end{array}$ & $\begin{array}{l}\text { Medial pale globe } \\
\text { Lateral pale globe }\end{array}$ \\
\hline $\begin{array}{l}\text { Substantia } \\
\text { nigra }\end{array}$ & & $\begin{array}{l}\text { Reticular part (RBS) } \\
\text { Compact part (CBS) }\end{array}$ \\
\hline $\begin{array}{l}\text { Striated } \\
\text { body }\end{array}$ & & Caudate putamen \\
\hline
\end{tabular}

glutamate. ${ }^{14,15}$ The pale-subthalamic pathway, whose projections represent most of the STN afferences, ${ }^{12}$ has GABA as a neurotransmitter. ${ }^{16}$ The brainstem projections for the STN originate in the substantia nigra, both in rodents and primates, and in humans. ${ }^{17}$ Using dopamine as a neurotransmitter, these projections play a modulator role of the cortical and GABAergic glutaminic afferences for the STN. ${ }^{16}$

Considering the main efferences of the STN, the subthalamic-pallidal pathway represents most of the STN projections, and the subthalamic-nigral pathway in rodents present the neurotransmitter glutamate (-Fig. 2).$^{18,19}$

\section{Vascularization of the STN}

The STN is irrigated by the anterior chorioidea arteries, branches of the internal carotid artery, which emerges just above the origin of the posterior communicating artery. ${ }^{20}$ The drainage system is of the deep venous type. Through this, the deep cerebral veins, which flow into the internal cerebral vein, drain to the magna vein. ${ }^{20}$

\section{Neuropathological Considerations Related to the STN} Clinical studies of the Luys' STN emerged in 1884, when Ralph Canfield and James J. Putnam presented one of the first case reports of hemiballism. ${ }^{2}$ This fact was evidenced in the literature in the study by Martin (1927), apud Parent et $\mathrm{al}^{2}{ }^{2}$ which reviewed the world literature and found that 11 of the 12 patients previously reported with hemiballism presented lesions in the STN area, including two with lesions restricted to this, in addition to a case reported by the researcher himself of a small hemorrhage almost limited to the STN. ${ }^{2}$ In 1947, it was observed that the lesions of the STN connections could also produce contralateral hemichorea or hemiballism in men. ${ }^{2}$

Chorea is characterized by involuntary arrhythmic, rapid, abruptly, non-repetitive movements in time and with variable distribution, preferably distal. ${ }^{21,22}$ When chorea is limited by a dimidium of the body, it is called hemichoreia. ${ }^{21}$ It Is evident that most of the studied choric syndromes are associated with striated body, pale globe and STN atrophy. ${ }^{21}$

Ballism is characterized by involuntary hyperkinetic movements, mainly of the proximal part of the limbs, with ample displacement of the extremities due to the large amplitude of the movement. ${ }^{21}$ It is commonly manifested on a single side of the body, in which case, it is called hemiballism. When it affects only one member, it is called monoballism; If it affects both legs, it is called paraballism; And, if presented in widespread form, biballism. ${ }^{22}$ When the intensity of these movements is diminished, ballism becomes indistinguishable from chorea. ${ }^{22,23}$ Most of the hemiballism tables are associated with the lesion in the contralateral STN, and it is already understood that the same clinical picture is also related to the lesions in the afferent and efferent pathways of the nucleus, the striated body, the thalamus, the black substance and their interconnections. ${ }^{24-29}$ However, hemiballism caused by lesions in the STN is more severe than when occasioned by other reasons. ${ }^{29}$

In PD, which is characterized by tremor, bradykinesia, and spasticity, it is noted the depletion of the neurotransmitter dopamine. This disease stems mainly from a neurodegenerative process in the substantia nigra located in the mesencephalon. In this pathology, the STN is hyperactive, and the deep cerebral stimulation of the STN can improve stiffness and bradykinesia. ${ }^{27}$ During the last few years, deep brain stimulation (DBS) of STN has been established as a treatment for a selected group of PD patients. The surgery is solely directed to the treatment of the motor symptoms of PD. The symptoms that show improvement with the use of DBS in the STN and in the MPG are those of the off period (akinesia, stiffness, tremor), painful dystias and dyskinesias. ${ }^{28}$

Below are presented criteria that should always be obeyed in the selection of patients:

- Established diagnosis of PD.

- The patient should be obligatorily responsive to levodopa, except in cases of patients whose predominant symptom is tremor, which can be beneficiary of surgical treatment independently of the previous response to levodopa.

- Unsatisfactory control of motor symptoms with better clinical treatment. The response to levodopa in the preoperative period is the best predictor for positive response of the surgery. Patients with atypical parkinsonism, nonresponsive to levodopa, have a poor response with a deep cerebral stimulator implant.

- Have at least 5 years of disease.

- Objective of improvement of motor symptoms of tremor type, bradykinesia, and stiffness.

After the electrode implantation, the neurostimulator (also called the implantable pulse generator) is buried under general anesthesia, usually in the subclavicular region, very similar to a cardiac pacemaker. The extensor cords are tunneled under the subcutaneous plane, connecting the electrodes to the neurostimulator. The STN and the MPG are the most commonly used targets in DBS implantation for PD treatment. ${ }^{28}$

Apparently, the STN participates in the processing of motivation, based mainly on the anatomical notion that the STN is a unit of the limbic loop involving the prefrontal cortex, the nucleus accumbens and the MPG. ${ }^{26}$ Experimental motivation studies have established that STN lesions do not increase hunger, but rather stimulate food motivation, explaining the mechanisms of clinical reports of hyperphagia induced by lesions in the STN. ${ }^{27-31}$ 


\section{Conclusion}

The importance of the STN is explained by its connections with regions of great motor and non-motor importance, such as the cerebral cortex, the thalamus, the pale globe, the substantia nigra, the striated body, and the brainstem. Discovered in 1865 by Luys, the STN is a set of small nuclei located in the diencephalon, inferior to the thalamus and superior to the substantia nigra, which can be visualized in a posterior coronal section. Histologically, it is consisted of neurons distributed in a compact form and filled with a large number of blood vessels and scattered myelinated fibers. The advent of deep cerebral stimulation has granted STN great visibility. Studies emphasize that the stimulation of this nucleus really alleviates the motor symptoms of PD.

\section{Conflict of Interests}

The authors have no conflict of interests to declare.

\section{References}

1 Pearce JM. Thesubthalamicnucleus andJules BernardLuys (1828-97). J Neurol Neurosurg Psychiatry 2001;71(06):783

2 Parent A, Parent M, Leroux-Hugon V. Jules Bernard Luys: a singular figure of 19th century neurology. Can J Neurol Sci 2002;29(03):282-288

3 Hamani C, Saint-Cyr JA, Fraser J, Kaplitt M, Lozano AM. The subthalamic nucleus in the context of movement disorders. Brain 2004;127(Pt 1):4-20

4 Parent A. Jules Bernard Luys and the subthalamic nucleus. Mov Disord 2002;17(01):181-185

5 Chang HT, Kita H, Kitai ST. The fine structure of the rat subthalamic nucleus: an electron microscopic study. J Comp Neurol 1983;221(01):113-123

6 Iwahori N. A Golgi study on the subthalamic nucleus of the cat. J Comp Neurol 1978;182(03):383-397

7 Yelnik J, Percheron G. Subthalamic neurons in primates: a quantitative and comparative analysis. Neuroscience 1979;4(11): 1717-1743

8 Nambu A, Takada M, Inase M, Tokuno H. Dual somatotopical representations in the primate subthalamic nucleus: evidence for ordered but reversed body-map transformations from the primary motor cortex and the supplementary motor area. J Neurosci 1996;16(08):2671-2683

9 Sato F, Parent M, Levesque M, Parent A. Axonal branching pattern of neurons of the subthalamic nucleus in primates. J Comp Neurol 2000;424(01):142-152

10 Takada M, Tokuno H, Hamada I, et al. Organization of inputs from cingulate motor areas to basal ganglia in macaque monkey. Eur J Neurosci 2001;14(10):1633-1650

11 Nambu A, Tokuno H, Takada M. Functional significance of the cortico-subthalamo-pallidal 'hyperdirect' pathway. Neurosci Res 2002;43(02):111-117

12 Parent A, Hazrati LN. Functional anatomy of the basal ganglia. II. The place of subthalamic nucleus and external pallidum in basal ganglia circuitry. Brain Res Brain Res Rev 1995;20(01):128-154
13 Smith Y, Hazrati LN, Parent A. Efferent projections of the subthalamic nucleus in the squirrel monkey as studied by the PHA-L anterograde tracing method. J Comp Neurol 1990;294(02): 306-323

14 Moriizumi T, Nakamura Y, Kitao Y, Kudo M. Ultrastructural analyses of afferent terminals in the subthalamic nucleus of the cat with a combined degeneration and horseradish peroxidase tracing method. J Comp Neurol 1987;265(02):159-174

15 Romansky KV, Usunoff KG, Ivanov DP, Galabov GP. Corticosubthalamic projection in the cat: an electron microscopic study. Brain Res 1979;163(02):319-322

16 Fonnum F, Gottesfeld Z, Grofova I. Distribution of glutamate decarboxylase, choline acetyl-transferase and aromatic amino acid decarboxylase in the basal ganglia of normal and operated rats. Evidence for striatopallidal, striatoentopeduncular and striatonigral GABAergic fibres. Brain Res 1978;143(01):125-138

17 François C, Savy C, Jan C, Tande D, Hirsch EC, Yelnik J. Dopaminergic innervation of the subthalamic nucleus in the normal state, in MPTP-treated monkeys, and in Parkinson's disease patients. J Comp Neurol 2000;425(01):121-129

18 Joel D, Weiner I. The connections of the primate subthalamic nucleus: indirect pathways and the open-interconnected scheme of basal ganglia-thalamocortical circuitry. Brain Res Brain Res Rev 1997;23(1-2):62-78

19 Rinvik E, Ottersen OP. Terminals of subthalamonigral fibres are enriched with glutamate-like immunoreactivity: an electron microscopic, immunogold analysis in the cat. J Chem Neuroanat 1993;6(01):19-30

20 Ferreira A, Braga F. Anatomia microcirúrgica da artéria coroídea anterior. Arq Neuro Psiquist 1990;48(04):448-453

21 Mendes MF, de Andrade LA, Ferraz HB. [Chorea: clinical analysis of 119 cases]. Arq Neuropsiquiatr 1996;54(03):419-427

22 Barbeau A, Duvoisin RC, Gerstenbrand F, Lakke JP, Marsden CD, Stern G. Classification of extrapyramidal disorders. Proposal for an international classification and glossary of terms. J Neurol Sci 1981;51(02):311-327

23 Vidaković A, Dragasević N, Kostić VS. Hemiballism: report of 25 cases. J Neurol Neurosurg Psychiatry 1994;57(08):945-949

24 Lin JJ, Chang MK. Hemiballism-hemichorea and non-ketotic hyperglycaemia. J Neurol Neurosurg Psychiatry 1994;57(06): 748-750

25 Lee MS, Marsden CD. Movement disorders following lesions of the thalamus or subthalamic region. Mov Disord 1994;9(05): 493-507

26 Kargarfard M, Eetemadifar M, Mehrabi M, Maghzi AH, Hayatbakhsh MR. Fatigue, depression, and health-related quality of life in patients with multiple sclerosis in Isfahan, Iran. Eur J Neurol 2012;19(03):431-437

27 Baunez C, Yelnik J, Mallet L. Six questions on the subthalamic nucleus: lessons from animal models and from stimulated patients. Neuroscience 2011;198:193-204

28 Tosta ED Rieder, Carlos L. Borges, Vanderci. Doença de Parkinson: Recomendações. $1^{\underline{a}}$ ed. São Paulo: Omnifarma; 2010

29 Postuma RB, Lang AE. Hemiballism: revisiting a classic disorder. Lancet Neurol 2003;2(11):661-668

30 Coral P, Teive HAG, Werneck LC. Hemibalismo: relato de oito casos. Arq Neuropsiquiatr 2000;58(3A):698-703

31 Lang AE. Persistent hemiballismus with lesions outside the subthalamic nucleus. Can J Neurol Sci 1985;12(02):125-128 